\title{
Tailoring of Boehmite-Derived Aluminosilicate Aerogel Structure and Properties: Influence of Ti Addition
}

\author{
Frances I. Hurwitz, ${ }^{1}$ Haiquan Guo, ${ }^{2}$ Erik J. Sheets, ${ }^{3}$ Derek R. Miller, ${ }^{4}$ and Katy N. Newlin ${ }^{5}$ \\ ${ }^{1}$ Structures and Materials Division, NASA Glenn Research Center, 21000 Brookpark Rd., \\ Cleveland, $\mathrm{OH} 44135$, U.S.A. \\ ${ }^{2}$ Ohio Aerospace Institute, Cleveland, OH, U.S.A \\ ${ }^{3}$ Purdue University, W. Lafayette, IN, U. S. A. \\ ${ }^{4}$ Michigan State University, E. Lansing, MI, U.S.A. \\ ${ }^{5}$ University of Louisville, Louisville, KY, U.S.A.
}

\begin{abstract}
Aluminosilicate aerogels offer potential for extremely low thermal conductivities at temperatures greater than $900^{\circ} \mathrm{C}$, beyond where silica aerogels reach their upper temperature limits. Aerogels have been synthesized at various Al:Si ratios, including mullite compositions, using Boehmite $(\mathrm{AlOOH})$ as the $\mathrm{Al}$ source, and tetraethoxy orthosilicate as the Si precursor. The Boehmite-derived aerogels are found to form by a self-assembly process of AlOOH crystallites, with Si-O groups on the surface of an alumina skeleton. Morphology, surface area and pore size varies with the crystallite size of the starting Boehmite powder, as well as with synthesis parameters.
\end{abstract}

Ternary systems, including Al-Si-Ti aerogels incorporating a soluble Ti precursor, are possible with careful control of $\mathrm{pH}$. The addition of Ti influences sol viscosity, gelation time pore structure and pore size distribution, as well as phase formation on heat treatment.

\section{INTRODUCTION}

Aluminosilicate aerogels are of interest as constituents of thermal insulation systems with potential for use at temperatures higher than those attainable with silica aerogels, which densify and sinter at temperatures above $800^{\circ} \mathrm{C}$. It is anticipated that the effectiveness of aluminosilicate aerogels as thermal insulators will be influenced by their composition (Al:Si ratio), backbone structure, morphology, pore size distribution, physical and skeletal densities. The present study focuses on the synthesis of aluminosilicates from Boehmite precursors as the Al source, and tetraethylorthosilicate (TEOS) as the $\mathrm{Si}$ source. Titanium is introduced as a third metal in a ternary Al-Si-Ti system using titanium isopropoxide. The objectives of the work are to establish a fundamental understanding of the relationship among constituent ratios and synthesis parameters on aerogel structure and thermal properties, including densification and sintering, and to evaluate the effect of Ti addition on these properties. 


\section{EXPERIMENT}

Synthesis

Aluminosilicate aerogels were prepared by a method similar to that of $\mathrm{Aravind}^{2}$ at $\mathrm{Al}: \mathrm{Si}$ ratios of $8 \mathrm{Al}: 1 \mathrm{Si}$ and $3 \mathrm{Al}: 1 \mathrm{Si}$ using a number of different Boehmite powders which varied in crystallite size. An $\mathrm{Al}_{2} \mathrm{TiO}_{5}$ formulation was synthesized as a model compound. Boehmite $(\mathrm{AlOOH})$ powders designated as P2 (4.9 nm crystallite size), and T25 (6.9 nm crystallite size), were obtained from Sasol North America. The powders were dispersed in nitric acid solution or water, and sonicated using a Misonix 4000 ultrasonic processor with a 419A tip for 2 minutes at 60 percent power. The dispersed Boehmite was combined with a solution of TEOS in 200 proof ethanol which had been hydrolyzed for 60 minutes with a stoichiometric amount of water and catalyzed with nitric acid. In those formulations incorporating $\mathrm{Ti}$, titanium isopropoxide was added to the hydrolyzed TEOS at the end of the 60 minute hydrolysis time, at levels needed to achieve 2.5 to 10 mole percent titanium based. The combined sol was poured into polyethylene molds and held at either ambient temperature or $55^{\circ} \mathrm{C}$ for 24 hours, following which the hydrogels were extracted into 200 proof ethanol, and then supercritically dried using $\mathrm{CO}_{2}$.

\section{Characterization}

Dried gels were characterized by physical measurement to determine shrinkage and physical density. Skeletal density, was determined by helium pycnometry, and nitrogen adsorption/ desorption was used to determine BET surface area and pore size distribution. Chemical bonding structure of starting powders and aerogels were characterized by Fourier Transform Infrared spectroscopy (FTIR). Field Emission Scanning Electron Microscopy (FESEM) was performed on uncoated samples to characterize pore morphology. Thermal analysis of the aerogels was conducted using simultaneous Thermogravimetric Analysis and Differential Thermal Analysis (TGA/DTA) in helium to identify mass loss and phase transitions. X-ray diffraction analysis (XRD) is being used to characterize powders and aerogels, as well as identify phases in heattreated samples.

\section{DISCUSSION}

The aluminosilcate aerogels produced from Boehmite differ from those produced using $\mathrm{AlCl}_{3}$ and propylene oxide. Our prior work ${ }^{3}$ has shown the backbone of the Boehmite-derived aerogels is produced by a self-assembly of Boehmite crystallites, with Al-O-Si groups formed on the crystallite surface, and has fewer tetrahedral $\mathrm{AlO}_{4}$ groups than are obtained by the $\mathrm{AlCl}_{3}$ route. Surface areas are significantly lower using Boehmite as an Al precursor, but so are the combined shrinkages in gelation and supercritical drying.

The T25 precursor was more acidic when suspended in nitric acid solution ( $\mathrm{pH} \mathrm{1.5),} \mathrm{then} \mathrm{the}$ same formulation using P2 (pH 3). Both produced a pH 3 sol after combining with TEOS. The T25 also could be suspended in water ( $\mathrm{pH} 5.5$ ), which formed a mixed sol with $\mathrm{pH}$ 4.5-5.0, depending on $\mathrm{Al}$ :Si ratio. Addition of Ti to Si containing gels increased viscosity of the sol, and decreased gelation time; in some cases this resulted in trapping of bubbles in the hydrogel. At 10 mole $\% \mathrm{Ti}$, gelation occurred within one to two minutes. Five mole $\%$ Ti still enabled pouring of the sol into molds, and infiltration of blanket materials. The $\mathrm{Al}_{2} \mathrm{TiO}_{5}$ composition gelled more slowly. Physical densities were nominally $0.07-0.08 \mathrm{~g} / \mathrm{cm}^{3}$. 

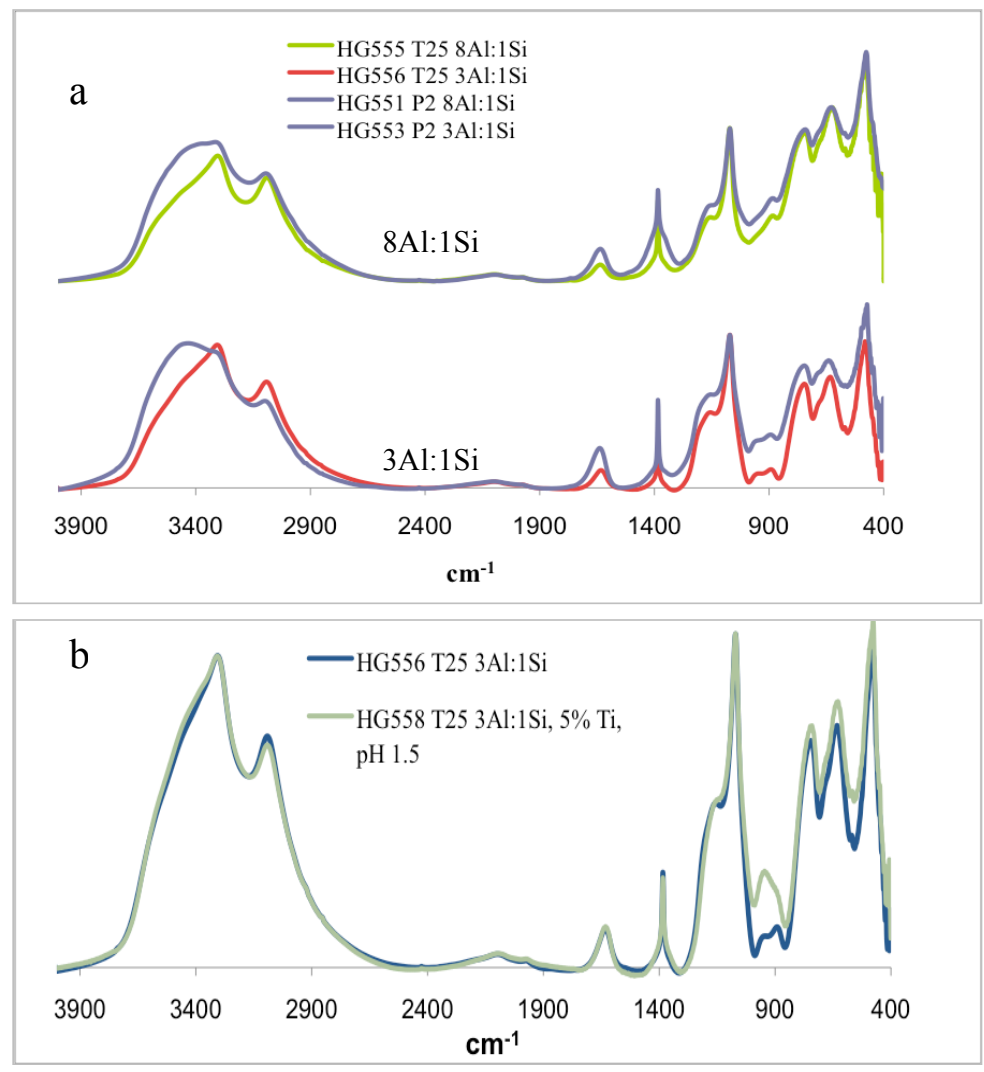

Figure 1. FTIR spectra of 8Al:1Si and 3Al:1Si aerogels prepared from $P 2$ and $T 25$ precursors (a). Influence of $T i$ addition in $T 25$ 3Al:1Si aergogel on IR spectra (b).

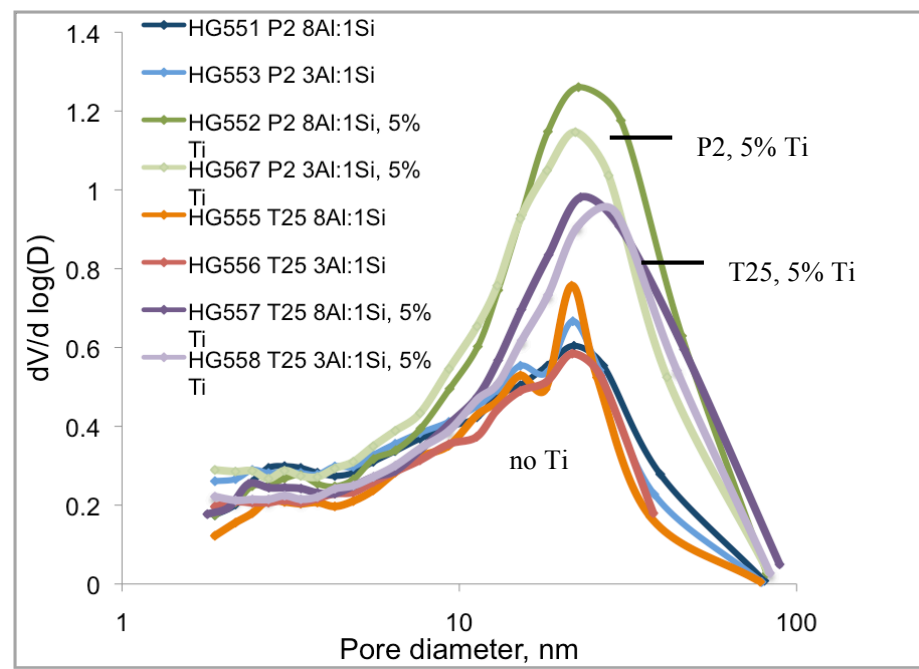

Figure 2. Pore size distribution of various aluminosilicate aerogels as determined by nitrogen desorption.

\section{FTIR characterization}

Fourier transform infrared spectra of representative $\mathrm{P} 2$ and $\mathrm{T} 25$ aerogels having $8 \mathrm{Al}: 1 \mathrm{Si}$ and $3 \mathrm{Al}: 1 \mathrm{Si}$ formulations are shown in Figure 1. Peaks at 3294, 3095, 1384, 1072, $736,620,474 \mathrm{~cm}^{-1}$ are characteristic of the starting $\mathrm{AlOOH}$ powders, consistent with $\mathrm{x}$-ray data that confirms the crystallite structure is unchanged with aerogel formation. The P2 powder itself, and associated aerogels, show more free $-\mathrm{OH}$, characterized by the presence of an $\mathrm{O}-\mathrm{H}$ stretching band near $3410 \mathrm{~cm}^{-1}$. The peaks at 1140 and $930 \mathrm{~cm}^{-1}$ increase in intensity with increasing Si content, reflecting additional Si-O bonding. An IR band at $945 \mathrm{~cm}^{-1}$, which can be attributed to Ti-O-Si bonding $^{4}$ was seen in $3 \mathrm{Al}: 1 \mathrm{Si}$ aerogels formulated with added $\mathrm{Ti}$ using the T25 Boehmite precursor, but not in the corresponding P2 formulations. This band is present in the T25 aerogels regardless of the $\mathrm{pH}$ of the initial T25 suspension, and might be influenced by the larger $d$ spacing $^{5}$ of the T25 crystallites compared to $\mathrm{P} 2$, as determined by $\mathrm{x}$-ray diffraction, or to lower associated free $\mathrm{OH}$ in the $\mathrm{T} 25$ preparations. The 945 $\mathrm{cm}^{-1}$ band is absent in the $\mathrm{Al}_{2} \mathrm{TiO}_{5}$, which contains no $\mathrm{Si}$.

\section{Surface area and pore size distribution}

Surface areas and pore size distribution of the as supercritically dried aerogels varied with Boehmite precursor, with the highest surface areas (344-444 $\mathrm{m}^{2} / \mathrm{g}$ ) obtained using the P2 powder at a $3 \mathrm{Al}: 1 \mathrm{Si}$ ratio. Surface areas for the T25 formulations ranged from $278-316 \mathrm{~m}^{2} / \mathrm{g}$. The addition of Ti using either P2 or T25 increased the frequency of larger nanopores, as shown in Figure 2. The highest frequency of larger pores, and highest pore volume occurred with incorporation of $\mathrm{Ti}$ in the $\mathrm{P} 2$ system. 


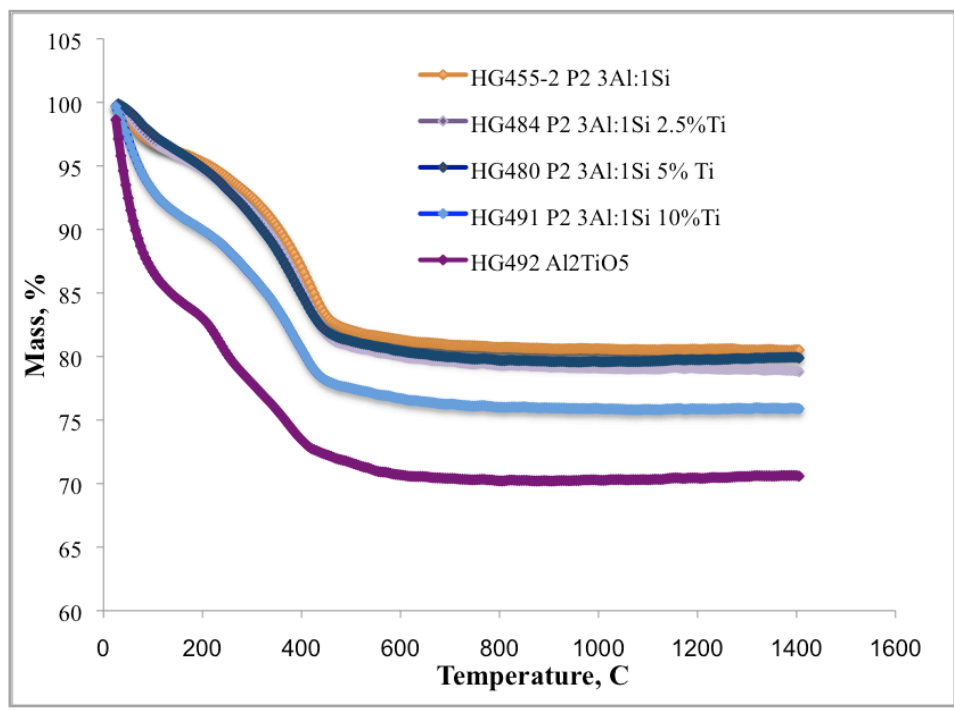

Figure 3. Thermogravimetric analysis of P2 3Al:1Si aerogels with various levels of $\mathrm{Ti}$ incorporation, and of an $\mathrm{Al}_{2} \mathrm{TiO}_{5}$ aerogel. Measurement is in $\mathrm{He}$.

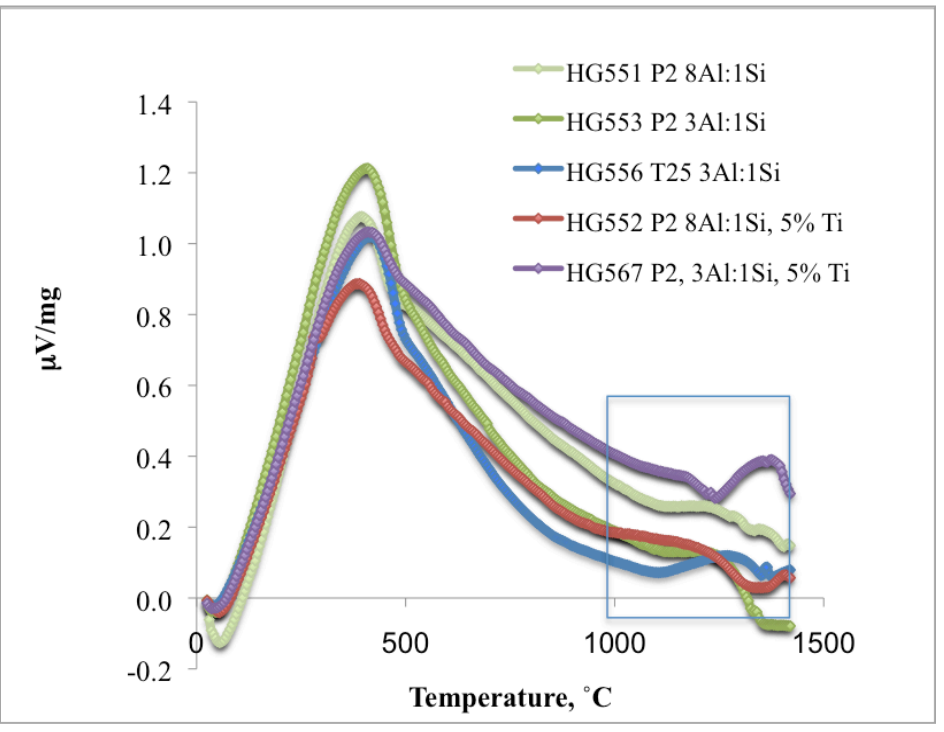

Figure 4. Representative DTA plots for various P2 and T25 formulations. Note complex phase transition behavior at high temperatures (blue box). Measurement is in $\mathrm{He}$ at $10^{\circ} \mathrm{C} / \mathrm{m}$.

\section{TGA/DTA characterization}

Ti incorporation also influences the thermal behavior of the aerogels (Figure 3), increasing the mass loss between ambient temperature and $120^{\circ} \mathrm{C}$, and significantly decreasing the mass yield at $1400^{\circ} \mathrm{C}$ from $80 \%$ in the $3 \mathrm{Al}: 1 \mathrm{Si}$ aerogels without $\mathrm{Ti}$ to 76 and $70 \%$ with 10 mole percent $\mathrm{Ti}$ and in the $\mathrm{Al}_{2} \mathrm{TiO}_{5}$ formulation. There is little decrement in final mass at the 5\% Ti level. There also appears to be an additional transition at $250-275^{\circ} \mathrm{C}$ in the $\mathrm{Al}_{2} \mathrm{TiO}_{5}$ curve.

The DTA curves (Figure 4) are characterized by a phase transition between 395 and $435^{\circ} \mathrm{C}$ associated with conversion of $\gamma-\mathrm{AlOOH}$ to $\gamma$ $\mathrm{Al}_{2} \mathrm{O}_{3}{ }^{6}$. The peak position shifts with the crystallite size of the precursor, occurring at higher temperature for the larger T25 crystallite size compared with the corresponding formulation for P2. The transition temperature also decreases with increasing $\mathrm{Al}$ content, as well as with Ti addition. The $980^{\circ} \mathrm{C}$ peak associated with mullite formation in the 3Al:1Si aerogels synthesized from $\mathrm{AlCl}_{3}$ is absent in the $3 \mathrm{~A}: 1 \mathrm{Si}$ Boehmite-derived aerogels.

Above $1000^{\circ} \mathrm{C}$ a number of phase transitions are evident, varying with aerogel type. X-ray diffraction analysis of aerogels heated to temperatures in the range from 1000$1425^{\circ} \mathrm{C}$ to identify phase formation is in progress.

\section{Microstructural characterization}

Of particular interest is identification of the temperatures at which nano- and mesoporosity is lost, and grain growth occurs, as this will have a major influence in increasing thermal conductivity, by both gas phase and solid conduction. FESEM images of P2 3Al:1Si aerogels as supercritically dried and after heating to $1425^{\circ} \mathrm{C}$ (post DTA) are shown in Figure 5. The P2, $3 \mathrm{Al}: 1 \mathrm{Si}$ formulations produced the highest surface area $\left(379-443 \mathrm{~m}^{2} / \mathrm{g}\right)$, with the exception of 
P2-derived $\mathrm{Al}_{2} \mathrm{TiO}_{5}$, and the smallest average pore diameter at $7.48 \mathrm{~nm}$. Addition of Ti increases both surface area and the population of larger pores. The un-doped 3Al:1Si formulation also exhibits the smallest grain size microstructure after brief heating to $1425^{\circ} \mathrm{C}$, with a substantial number of small pores maintained. Note the larger grain sizes and large pores obtained from the P2 8Al:1 Si and $\mathrm{Al}_{2} \mathrm{TiO}_{5}$ formulations after heat treatment (Figure 6).
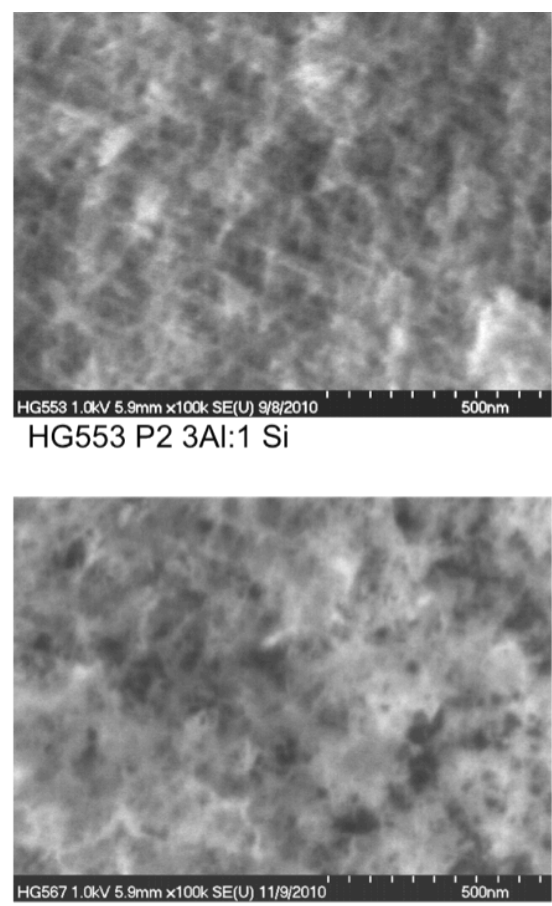

HG567 P2 3Al:1 Si, 5\% Ti
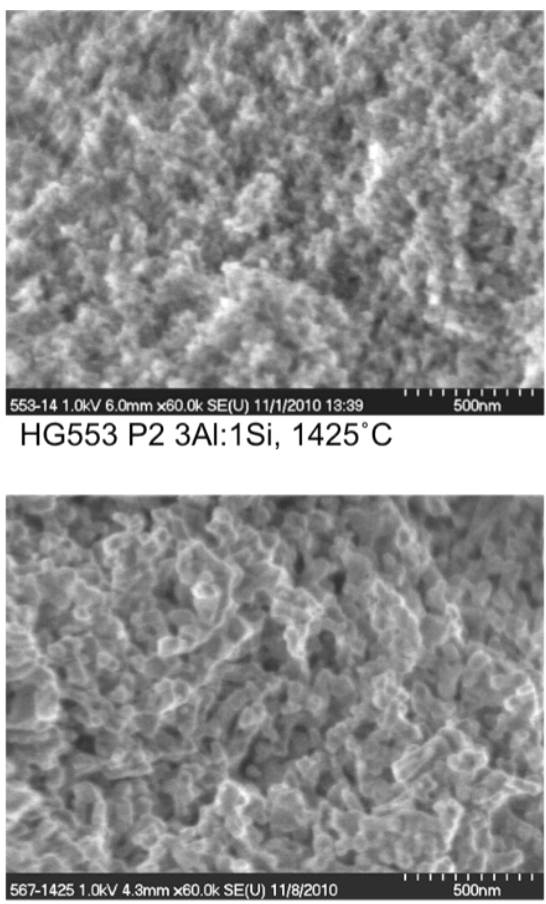

HG567 P2 3Al:1Si, 5\% Ti, $1425^{\circ} \mathrm{C}$

Figure 5. FESEM images of P2 3Al:1Si as- supercritically dried (left) and after heating to $1425^{\circ} \mathrm{C}$ (right), showing coarsening of backbone structure due to crystallization on heating.

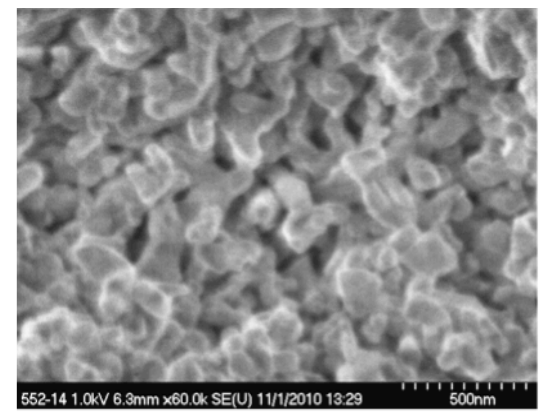

HG552 P2 8Al:1Si, 5\% Ti, $1425^{\circ} \mathrm{C}$

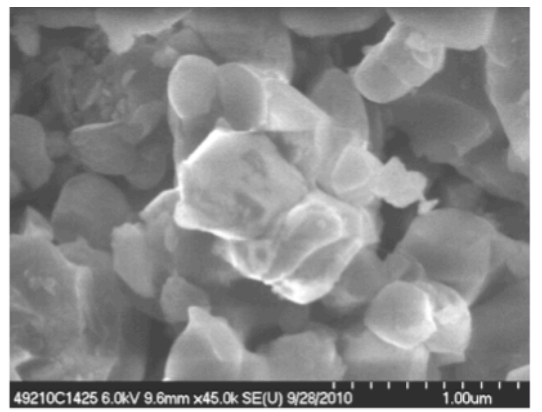

$\mathrm{HG} 492 \mathrm{P} 2 \mathrm{Al}_{2} \mathrm{TiO}_{5}, 1425^{\circ} \mathrm{C}$

Figure 6. $\mathrm{P2}$ derived 8Al:1Si (left) and $\mathrm{Al}_{2} \mathrm{TiO}_{5}$ aerogels (right) after heating to $1425^{\circ} \mathrm{C}$. Note difference in scale between the two images. 


\section{CONCLUSIONS}

The aluminosilicate aerogels derived from Boehmite differ in backbone structure from those produced from $\mathrm{AlCl}_{3}$, most notably in maintaining a primarily $\mathrm{AlO}_{6}$ structure, with few tetrahedral $\mathrm{AlO}_{4}$ groups, as compared with $\mathrm{AlCl}_{3}$ derived aerogels. The smaller crystallite, $\mathrm{P} 2$ powders produce higher surface area and higher pore volume microstructures than corresponding T25 aerogels, and seem to offer preservation of fine pore structures at high temperature. However, surface area of the as-dried aerogels is not a discriminator for predicting high temperature microstructure.

Introduction of $\mathrm{Ti}$ at the molecular level using a $\mathrm{Ti}$ isopropoxide precursor in systems containing $\mathrm{Si}$ increases sol viscosity and decreases gel time, limiting $\mathrm{Ti}$ incorporation to nominally 10 mole percent; this might prove advantageous where control of viscosity and gel time is needed. Reaction of Si and Ti groups appears higher using T25 than P2 precursors; solid state ${ }^{27} \mathrm{Al}$ and ${ }^{29} \mathrm{Si}$ nuclear magnetic resonance characterization is in progress to further define bonding structures. Without Si present, a composition of $\mathrm{Al}_{2} \mathrm{TiO}_{5}$, having 33 percent $\mathrm{Ti}$, can be obtained; but these systems, while among the highest in surface area after supercritical drying, show substantial grain growth after exposure to $1425^{\circ} \mathrm{C}$. Additional work on relating thermal exposure to crystallization and grain growth is needed to define upper use temperatures for these systems as insulating materials.

\section{ACKNOWLEDGMENTS}

The authors wish to thank Anna Palczer, Richard Rogers, Ph.D. and Dereck Johnson, NASA Glenn Research Center, and the Hypersonics Project under the NASA Fundamental Aeronautics Program as well as the NASA Radioisotope Power Systems Project for funding.

\section{REFERENCES}

(1) Hench, L., West, J., Chem. Rev. 1990, 33-72.

(2) Aravind, P. R.; Mukundan, P.; Krishna Pillai, P.; Warrier, K. G. K. Microporous and Mesoporous Materials 96, 14 (2004).

(3) Hurwitz, F. I., Guo, H., Sheets, E. J., Liou, D-Y., Olin, T. C., Ittes, M. A. American Chemical Society Spring 2010 National Meeting, San Francisco, CA March 21-25, 2010, unpublished.

(4) Dutiot, D. C. M., Schneider, M., Baiker, A., J. Catalysis 153, 165-176 (1995).

(5) Brühne, S., Gottleib, S., Assmus, W., Alig, E., Schmidt, M. U., Cryst. Growth Des. 8 (2), 489-493n (2008).

(6) Pecharrromán, C; Sobrados, I.; Iglesias, J. A.; González-Carreño, T.; Sanz, J. J. Phys. Chem. $B, \mathbf{1 0 3}, 6160-6170$ (1999). 